\title{
Extracorporeal photopheresis: tolerogenic or immunogenic cell death? Beyond current dogma
}

\author{
Dalil Hannani* \\ PDC*line Pharma SAS, Grenoble, France
}

Keywords: extracorporeal photopheresis, GvHD, CTCL, transplantation, cancer, T cell vaccination, anti-clonotypic response, immunogenic cell death

Extracorporeal photopheresis (ECP) is an autologous cell therapy that is widely used for the treatment of $\mathrm{T}$ cell-mediated diseases. ECP has been FDA-approved for the treatment of cutaneous $\mathrm{T}$ cell lymphoma (CTCL) and has shown potent clinical benefits in various other (noncancer) $\mathrm{T}$ cell-mediated diseases, such as graft versus host disease (GvHD), allograft rejection, as well as in autoimmune disorders, such as rheumatoid arthritis, psoriasis, systemic sclerosis, type 1 diabetes, and Crohn's disease (1-3). The ECP treatment consists in the irradiation by UV-A in presence of a photosensitizer agent (8-methoxypsoralen) of PBMCs collected by apheresis (4). This will lead to an irreversible DNA crosslink by the psoralen, culminating by the apoptosis of virtually all the treated cells $(5,6)$. Then, the treated cells are re-infused to the patient. This repeated process leads to the improvement in patients' clinical status, allowing the

OPEN ACCESS

Edited by:

Philippe Saas,

Etablissement Français du Sang Bourgogne-Franche-Comté, France

Reviewed by:

Sylvain Perruche,

Institut national de la santé et de la recherche médicale, France

*Correspondence:

Dalil Hannani

d.hannani@pdc-line-pharma.com

Specialty section:

This article was submitted to Alloimmunity and Transplantation, a section of the journal

Frontiers in Immunology

Received: 30 March 2015 Accepted: 24 June 2015 Published: 07 July 2015

Citation:

Hannani D (2015) Extracorporeal photopheresis: tolerogenic or immunogenic cell death? Beyond current dogma.

Front. Immunol. 6:349. doi: 10.3389/fimmu.2015.00349 decrease or the disappearance of tumoral T cells in CTCL, or a decrease or a total disruption of immunosuppressive drugs, thus avoiding steroid-related side effects in GvHD (7). ECP has also shown benefits in cortico-refractory patients (8). Conversely to immunosuppressive treatments, ECP seems to selectively target allo- and auto-reactive T cells in GvHD and autoimmune diseases, respectively (called pathogenic $\mathrm{T}$ cells hereafter), without inducing systemic immunosuppression (9). Today, even if ECP has created real hopes for the treatment of these pathologies, its implementation is quite limited due to a relative empiric utilization due to the absence of prospective randomized clinical trials and a lack in the understanding of its mechanism of action (MoA).

For instance, ECP is thought to act through the induction of immune tolerance in GvHD. Indeed, Gatza et al. have described that the injection of ECP-treated splenocytes from mice developing GvHD (i.e., containing allogeneic T cells) triggers IL-10-producing regulatory T cells (Tregs) able to reverse experimental GvHD (10). However, authors did not assess whether or not ECP-induced Tregs were alloantigen specific (i.e., that ECP does not induces a systemic tolerance in this setting) in order to fully recapitulate the clinical situation observed in humans.

The infusion of apoptotic cells has previously been described as promoting tolerance. Notably, the infusion of $\gamma$-irradiated apoptotic splenocytes, concomitantly with bone marrow cells, triggers the generation of TGF- $\beta$-dependent Tregs, which in turn favors the bone marrow cells' engraftment as well as protects from GvHD occurrence (11). A similar approach has recently been evaluated in a phase I/IIa clinical trial as prophylaxis for GvHD, where donor apoptotic cells have been injected to recipient 1 day before bone marrow transplantation (BMT), and has shown encouraging results (12). In line with this, some studies proposed to use ECP-treated autologous cells as a prophylactic treatment of GvHD (13). This therapeutic setting prevents or at least diminishes the occurrence of acute GvHD by inducing Tregs, in a host IL-10-production-dependent manner in mice. In both of these settings, prior massive infusion of apoptotic cells might induce systemic immune tolerance, which in turn diminishes or prevents acute GvHD development following BMT. In an in vitro model, Di Renzo et al. have shown that monocyte-derived dendritic cells 
(DCs) from GvHD patients secreted an increased amount of IL-10 when stimulated by LPS in presence of autologous ECP-treated T cells (14).

Altogether these data indicate that ECP might be able to induce, at least in part, immune tolerance. However, the generation of Tregs as a unique mechanism neither explains how ECP selectively targets pathogenic $\mathrm{T}$ cells without inducing a systemic immunosuppression (9) nor how it works in CTCL. Indeed, the hypothesis that has been made concerning its MoA in CTCL is rather the elicitation of an anti-tumor response directed toward tumoral $\mathrm{T}$ cells (9). How ECP could trigger both an anti-tumor immune response and immune tolerance remains an open question.

The pathologies treated by ECP are heterogeneous; however, they are all mediated by a (oligo)-clonal T cell population (tumoral $\mathrm{T}$ cell clones in CTCL, allo- or auto-reactive oligoclonal $\mathrm{T}$ cells in GvHD and autoimmune diseases). Thus, these $\mathrm{T}$ cells share unique or a few $\mathrm{T}$ cell receptors (TcR) representing pathogenic $T$ cell-specific antigens that can be subsequently targeted by ECPinduced immune responses.

Importantly, the presence of this pathogenic $\mathrm{T}$ cell population within the treated cells is critical for the ECP efficacy (15). This observation has also been made recently in an animal model in which ECP was efficient only when pathogenic, and not naive $\mathrm{T}$ cells, were treated (16). Interestingly, these observations are in line with the seminal work pioneered by Irun Cohen that has developed the $\mathrm{T}$ cell vaccination (TCV) concept, showing that the injection of altered activated pathogenic $T$ cells results in the systemic control of untreated pathogenic $\mathrm{T}$ cells by triggering anti-clonotypic cytotoxic CD8 T cells. (17-19). Of note, clinical trial have been performed, using TCV in multiple sclerosis (MS), and have shown very encouraging results (20). Zhang and colleagues have been the firsts testing this concept in humans (21). In this study, MBP-reactive T cells have been isolated and amplified ex vivo from MS patients. Then, amplified activated pathogenic $\mathrm{T}$ cells have been irradiated and then infused back to the patient. This treatment has led to clinical responses, illustrated by the disappearance of pathogenic T cells (i.e., untreated MBPreactive $\mathrm{T}$ cells). This clinical response is due to the generation of anti-clonotypic CD8 T cells, which are able to eliminate pathogenic $\mathrm{T}$ cells in a cytotoxic-dependent manner (21). Thus, altogether, these critical data underlie the necessity of providing dying pathogenic $\mathrm{T}$ cells (containing specific antigens) in order to obtain a therapeutic response, evoking an anti-(oligo)clonotypic immune response triggered by the repeated re-infusion of treated pathogenic T cells.

Until recently, apoptosis has been described as a silent/ tolerogenic process, where dying cells either die «silently» or actively secrete - and/or induce the production of - antiinflammatory cytokines, such as IL-10 and TGF- $\beta$ (22). During the last decade, Zitvogel's group has published a seminal work describing that in particular conditions, tumor cell death could be an immunogenic process, able to elicit an immune response directed toward this population $(23,24)$. At least four events are mandatory for undergoing an immunogenic cell death (ICD) as follows: (1) the membrane exposure of calreticulin (CRT) following a pre-mortem endoplasmic reticulum (ER) stress response. This favor the phagocytosis of dying cells (25); (2) the release of a nuclear protein that acts as an alarmin in the extracellular environment, high-mobility group box (HMGB)-1 (26); (3) the release of ATP that favors the production of IL-1 $\beta$ (27) as well as the attraction and differentiation of antigen presenting cells (APCs) (28); and (4) the activation of autophagy machinery that is critical for ATP release (29). ICD has been described in the context of chemotherapy-induced tumor cell death, and has been recently evidenced following photodynamic therapy (30). However, to date, whether ECP induces ICD is still unknown.

Extracorporeal photopheresis-induced ICD would support the anti-clonotypic response hypothesis in CTCL. Indeed, the reinfusion of tumoral T cells undergoing ICD back to the patient would facilitate DC-mediated phagocytosis as well as DC maturation. Of note, Yakut et al. have shown that ECP actually promotes IL-1 $\beta$ production by ECP-treated DCs (31). Since IL- $1 \beta$ is a key cytokine involved in ICD-induced anti-tumor responses $(23,24,27)$, IL-1 $\beta$-producing DCs would be, in turn, able to initiate an anti-tumor immune response directed toward living cancer cells. Importantly, ECP-induced ICD could also support this hypothesis in GvHD (and solid organ transplantation and autoimmunity disorders) as well. Indeed, in these pathologies, oligoclonal pathogenic T cells may represent an important proportion of circulating $\mathrm{T}$ cells - therefore, an important proportion among treated cells - and are in an activated state (because of undergoing allo- or auto-immunity). Interestingly, it has been shown that activated $\mathrm{T}$ cells die more rapidly than resting $\mathrm{T}$ cells following ECP treatment (32). It means that during the first hours following re-infusion of treated cells, only pathogenic $\mathrm{T}$ cells undergo (immunogenic?) cell death. In these conditions, they become the unique source of antigens. Thus, this window of time allows the preferential phagocytosis of dying pathogenic $\mathrm{T}$ cells by APCs, and subsequent antigen processing and presentation to the immune system. Of note, Johansson and colleagues have shown that in presence of activated, but not resting, apoptotic $\mathrm{T}$ cells, autologous DCs acquired a mature phenotype and produce pro-inflammatory cytokines (33). Importantly, DCs exposed to allogeneic, activated apoptotic $\mathrm{T}$ cells induce the proliferation and IFN $\gamma$ production by autologous $\mathrm{T}$ cells. In this setting, pathogenic activated $\mathrm{T}$ cell TcR-derived peptides could be presented to the immune system, leading to the elicitation of an anti-(oligo)clonotypic immune response, targeting the pathogenic (oligo)clonal $\mathrm{T}$ cell population (Figure 1). This scenario would explain why the presence of pathogenic T cells is critical for reaching therapeutic success, as well as, how ECP induces a specific control of alloreactive $\mathrm{T}$ cells responsible for GvHD and solid organ rejection, or autoimmune $\mathrm{T}$ cells involved in autoimmune disorders, without inducing generalized immunosuppression (i.e., by eradicating specifically the pathogenic T cells). Ayyildiz et al. have reported that the serum TNF- $\alpha$ level decrease 1 day after ECP treatment in chronic GvHD (34). Interestingly, during the first ECP treatments, the serum TNF- $\alpha$ level fluctuates and it is found as high as baseline prior to the second ECP treatment. It is likely that ECP first induces a transient immune tolerance due to the infusion of large quantity of apoptotic cells, as described in other settings $(11,13)$. However, following several ECP sessions, the serum TNF- $\alpha$ level tends to stably decrease in responding patients (34). It is conceivable that ECP-induced 


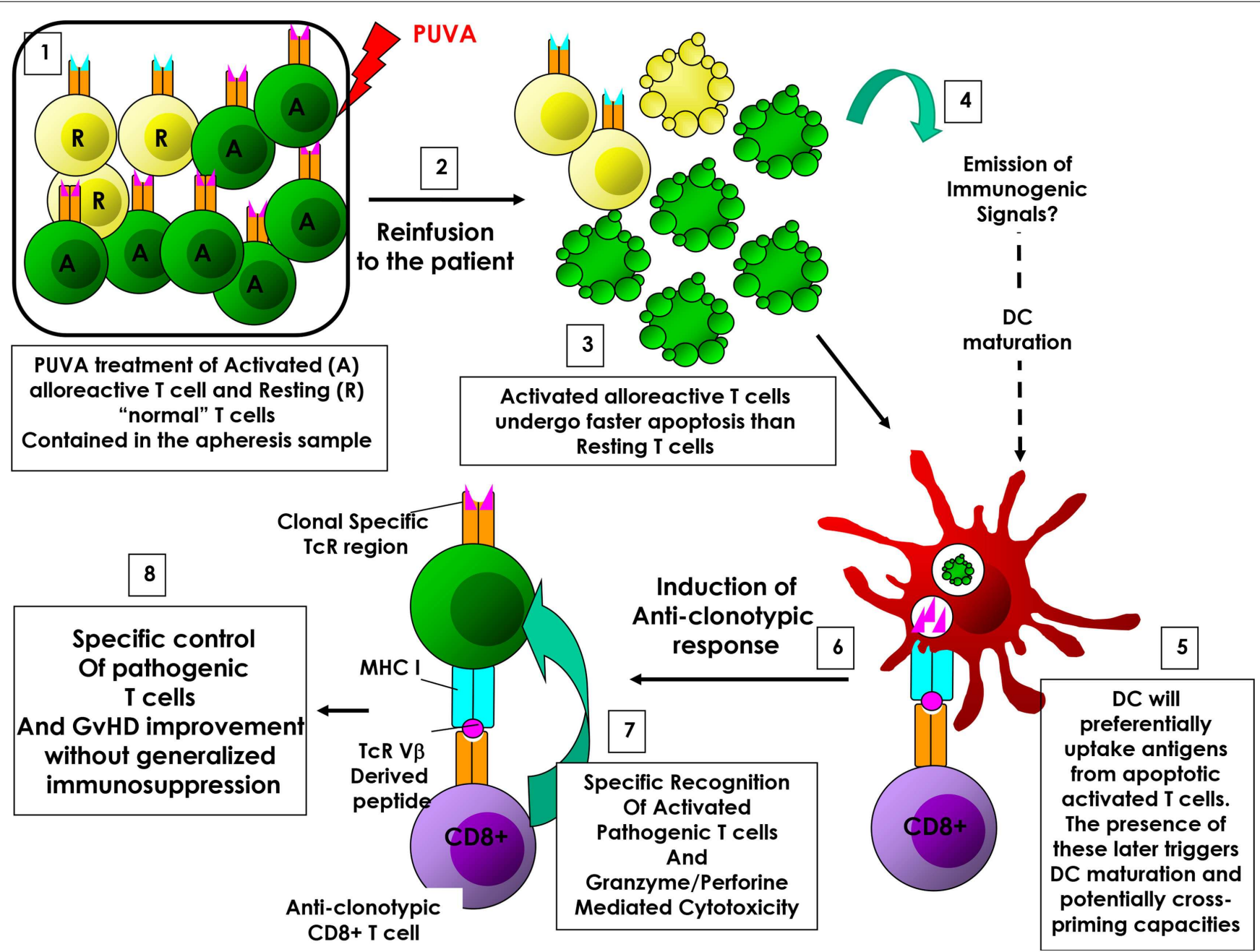

FIGURE 1 | ECP-induced anti-clonotypic response in GvHD.

(1) (Oligo)clonal activated alloreactive T cells are enriched compared to «normal» resting $T$ cells among treated cells. (2) Cells are re-infused back to the patient. (3) Activated T cells undergo apoptosis faster than resting $T$ cells. (4) Emission of immunogenic signals. (5) During this window of time, dying activated $T$ cells will be preferentially phagocytized by dendritic cells (DCs), representing the main source of antigen. (6) DCs will then process and present alloreactive associated T cells antigens (i.e., TcR-derived peptides), allowing the elicitation of an anti-clonotypic response. (7) Anti-clonotypic T cells will then specifically recognize and eradicate alloreactive T cells. (8) The eradication of alloreactive T cells will lead to the improvement of GvHD without inducing systemic immunosuppression. transient immune tolerance could be paralleled and/or followed by the generation of anti-clonotypic responses, which would indirectly trigger a steady TNF- $\alpha$ decrease by eliminating pathogenic $\mathrm{T}$ cells. Indeed, ECP-induced ICD of pathogenic T cells could reconcile the apparently contradictory MoAs proposed so far (triggering immunity in CTCL and immune tolerance in GvHD). Understanding ECPs MoA will help considerably in rationalizing treatment schedules and processes as well as its application field. Finally, it is a critical step toward identifying a predictive

\section{References}

1. Wolff $\mathrm{D}$, Schleuning $\mathrm{M}$, von Harsdorf $\mathrm{S}$, Bacher $\mathrm{U}$, Gerbitz A, Stadler $\mathrm{M}$, et al. Consensus conference on clinical practice in chronic GVHD: second-line treatment of chronic graft-versus-host disease. Biol Blood Marrow Transplant (2011) 17(1):1-17. doi:10.1016/j.bbmt.2010. 05.011 biomarker of efficacy for improving the patients' response rates and for proposing synergizing combinatory therapy for rescuing unresponsive patients.

This short opinion article provides an original point of view in this field and proposes a MoA in which ECP induces an immunogenic, rather than a tolerogenic, cell death. This scenario is the only one describing a unique MoA able to explain the efficacy of ECP in such different pathologies, and therefore, strongly deserves to be fully investigated.

2. Trautinger F, Just U, Knobler R. Photopheresis (extracorporeal photochemotherapy). Photochem Photobiol Sci (2013) 12(1):22-8. doi:10.1039/ C2PP25144B

3. Ward DM. Extracorporeal photopheresis: how, when, and why. J Clin Apher (2011) 26(5):276-85. doi:10.1002/jca.20300

4. Garban F, Makowski C, Carras S, Drillat P, Gressin R, ves Cahn JY, et al. Extracorporeal photopheresis: scientific and technical considerations for improving 
clinical managemeent of patients. J Stem Cell Res Ther (2014) 4(9):232. doi:10. 4172/2157-7633.1000232

5. Bladon J, Taylor PC. Extracorporeal photopheresis induces apoptosis in the lymphocytes of cutaneous T-cell lymphoma and graft-versus-host disease patients. Br J Haematol (1999) 107(4):707-11. doi:10.1046/j.1365-2141.1999. 01773.x

6. Hannani D, Gabert F, Laurin D, Sall M, Molens JP, Hequet O, et al. Photochemotherapy induces the apoptosis of monocytes without impairing their function. Transplantation (2010) 89(5):492-9. doi:10.1097/TP. 0b013e3181c6ffd3

7. Flowers ME, Apperley JF, van Besien K, Elmaagacli A, Grigg A, Reddy V, et al. A multicenter prospective phase 2 randomized study of extracorporeal photopheresis for treatment of chronic graft-versus-host disease. Blood (2008) 112(7):2667-74. doi:10.1182/blood-2008-03-141481

8. Abu-Dalle I, Reljic T, Nishihori T, Antar A, Bazarbachi A, Djulbegovic B, et al. Extracorporeal photopheresis in steroid-refractory acute or chronic graftversus-host disease: results of a systematic review of prospective studies. Biol Blood Marrow Transplant (2014) 20(11):1677-86. doi:10.1016/j.bbmt.2014.05. 017

9. Marshall SR. Technology insight: ECP for the treatment of GvHD - can we offer selective immune control without generalized immunosuppression? Nat Clin Pract Oncol (2006) 3(6):302-14. doi:10.1038/ncponc0511

10. Gatza E, Rogers CE, Clouthier SG, Lowler KP, Tawara I, Liu C, et al. Extracorporeal photopheresis reverses experimental graft-versus-host disease through regulatory T cells. Blood (2008) 112(4):1515-21. doi:10.1182/ blood-2007-11-125542

11. Kleinclauss F, Perruche S, Masson E, de Carvalho Bittencourt M, Biichle S, Remy-Martin JP, et al. Intravenous apoptotic spleen cell infusion induces a TGF-beta-dependent regulatory T-cell expansion. Cell Death Differ (2006) 13(1):41-52. doi:10.1038/sj.cdd.4401699

12. Mevorach D, Zuckerman T, Reiner I, Shimoni A, Samuel S, Nagler A, et al. Single infusion of donor mononuclear early apoptotic cells as prophylaxis for graft-versus-host disease in myeloablative HLA-matched allogeneic bone marrow transplantation: a phase I/IIa clinical trial. Biol Blood Marrow Transplant (2014) 20(1):58-65. doi:10.1016/j.bbmt.2013.10.010

13. Florek M, Sega EI, Leveson-Gower DB, Baker J, Müller AM, Schneidawind D, et al. Autologous apoptotic cells preceding transplantation enhance survival in lethal murine graft-versus-host models. Blood (2014) 124(11):1832-42. doi:10. 1182/blood-2014-02-555128

14. Di Renzo M, Sbano P, De Aloe G, Pasqui AL, Rubegni P, Ghezzi A, et al. Extracorporeal photopheresis affects co-stimulatory molecule expression and interleukin-10 production by dendritic cells in graft-versus-host disease patients. Clin Exp Immunol (2008) 151(3):407-13. doi:10.1111/j.1365-2249. 2007.03577.x

15. French LE, Alcindor T, Shapiro M, McGinnis KS, Margolis DJ, Porter D, et al. Identification of amplified clonal $\mathrm{T}$ cell populations in the blood of patients with chronic graft-versus-host disease: positive correlation with response to photopheresis. Bone Marrow Transplant (2002) 30(8):509-15. doi:10.1038/sj. bmt.1703705

16. Budde H, Kolb S, Salinas Tejedor L, Wulf G, Reichardt HM, Riggert J, et al. Modified extracorporeal photopheresis with cells from a healthy donor for acute graft-versus-host disease in a mouse model. PLoS One (2014) 9(8):e105896. doi:10.1371/journal.pone.0105896

17. Cohen IR, Quintana FJ, Mimran A. Tregs in T cell vaccination: exploring the regulation of regulation. J Clin Invest (2004) 114(9):1227-32. doi:10.1172/ JCI23396

18. Jiang $\mathrm{H}$, Chess $\mathrm{L}$. An integrated view of suppressor $\mathrm{T}$ cell subsets in immunoregulation. J Clin Invest (2004) 114(9):1198-208. doi:10.1172/JCI23411

19. Kumar V. Homeostatic control of immunity by TCR peptide-specific Tregs. J Clin Invest (2004) 114(9):1222-6. doi:10.1172/JCI23166

20. Kumar V, Sercarz E, Zhang J, Cohen I. T-cell vaccination: from basics to the clinic. Trends Immunol (2001) 22(10):539-40. doi:10.1016/S1471-4906(01) 02020-8
21. Zhang J, Medaer R, Stinissen P, Hafler D, Raus J. MHC-restricted depletion of human myelin basic protein-reactive T cells by T cell vaccination. Science (1993) 261(5127):1451-4. doi:10.1126/science.7690157

22. Girkontaite I, Urbonaviciute V, Maseda D, Neubert K, Herrmann M, Voll RE. Apoptotic cells selectively suppress the Th1 cytokine interferon gamma in stimulated human peripheral blood mononuclear cells and shift the Th1/Th2 balance towards Th2. Autoimmunity (2007) 40(4):327-30. doi:10. 1080/08916930701356846

23. Hannani D, Sistigu A, Kepp O, Galluzzi L, Kroemer G, Zitvogel L. Prerequisites for the antitumor vaccine-like effect of chemotherapy and radiotherapy. Cancer $J$ (2011) 17(5):351-8. doi:10.1097/PPO.0b013e3182325d4d

24. Kroemer G, Galluzzi L, Kepp O, Zitvogel L. Immunogenic cell death in cancer therapy. Annu Rev Immunol (2013) 31:51-72. doi:10.1146/annurevimmunol-032712-100008

25. Obeid M, Tesniere A, Ghiringhelli F, Fimia GM, Apetoh L, Perfettini JL, et al. Calreticulin exposure dictates the immunogenicity of cancer cell death. Nat Med (2007) 13(1):54-61. doi:10.1038/nm1523

26. Apetoh L, Ghiringhelli F, Tesniere A, Obeid M, Ortiz C, Criollo A. Tolllike receptor 4-dependent contribution of the immune system to anticancer chemotherapy and radiotherapy. Nat Med (2007) 13(9):1050-9. doi:10.1038/ $\mathrm{nm} 1622$

27. Ghiringhelli F, Apetoh L, Tesniere A, Aymeric L, Ma Y, Ortiz C, et al. Activation of the NLRP3 inflammasome in dendritic cells induces IL-1beta-dependent adaptive immunity against tumors. Nat Med (2009) 15(10):1170-8. doi:10.1038/ $\mathrm{nm} .2028$

28. Ma Y, Adjemian S, Mattarollo SR, Yamazaki T, Aymeric L, Yang H, et al. Anticancer chemotherapy-induced intratumoral recruitment and differentiation of antigen-presenting cells. Immunity (2013) 38(4):729-41. doi:10.1016/j.immuni. 2013.03.003

29. Michaud M, Martins I, Sukkurwala AQ, Adjemian S, Ma Y, Pellegatti P, et al. Autophagy-dependent anticancer immune responses induced by chemotherapeutic agents in mice. Science (2011) 334(6062):1573-7. doi:10.1126/science. 1208347

30. Garg AD, Agostinis P. ER stress, autophagy and immunogenic cell death in photodynamic therapy-induced anti-cancer immune responses. Photochem Photobiol Sci (2014) 13(3):474-87. doi:10.1039/c3pp50333j

31. Yakut E, Jakobs C, Peric A, Michel G, Baal N, Bein G, et al. Extracorporeal photopheresis promotes IL-1beta production. J Immunol (2015) 194(6):2569-77. doi:10.4049/jimmunol.1400694

32. Hannani D, Merlin E, Gabert F, Laurin D, Deméocq F, Chaperot L, et al. Photochemotherapy induces a faster apoptosis of alloreactive activated $\mathrm{T}$ cells than of nonalloreactive resting $\mathrm{T}$ cells in graft versus host disease. Transplantation (2010) 90(11):1232-8. doi:10.1097/TP.0b013e3181fa4eb6

33. Johansson U, Walther-Jallow L, Smed-Sörensen A, Spetz AL. Triggering of dendritic cell responses after exposure to activated, but not resting, apoptotic PBMCs. J Immunol (2007) 179(3):1711-20. doi:10.4049/jimmunol.179.3.1711

34. Ayyildiz E, Arslan O, Topçuoglu P, Arat M, Dalva K, Soydan EA, et al. The effect of extracorporeal photoimmunotherapy (ECP) on serum TNF-a level in chronic graft versus host disease (GvHD). Transfus Apher Sci (2007) 36(1):79-85. doi:10. 1016/j.transci.2006.06.007

Conflict of Interest Statement: The author declares that the research was conducted in the absence of any commercial or financial relationships that could be construed as a potential conflict of interest.

Copyright $\odot 2015$ Hannani. This is an open-access article distributed under the terms of the Creative Commons Attribution License (CC BY). The use, distribution or reproduction in other forums is permitted, provided the original author(s) or licensor are credited and that the original publication in this journal is cited, in accordance with accepted academic practice. No use, distribution or reproduction is permitted which does not comply with these terms. 